\title{
Healthcare workers' perception of their awareness, skills and attitudes towards clinical quality and patient safety in an acute care hospital in Singapore
}

\author{
Adeline Shuhan Koh*1, Zhixuan Zhang ${ }^{1}$, Ghee Hian Lim², Beng Leong Lim², Wei Ming Ng², Sze Joo Juan² \\ ${ }^{1}$ Department of Medical Affairs, Ng Teng Fong General Hospital, JurongHealth Campus, A Member of National University \\ Health System, Singapore \\ ${ }^{2}$ Department of Emergency Medicine, Ng Teng Fong General Hospital, JurongHealth Campus, A Member of National University \\ Health System, Singapore
}

Received: September 5, 2019

Accepted: November 11, 2019

Online Published: November 14, 2019

DOI: $10.5430 /$ jha.v8n6p41

URL: https://doi.org/10.5430/jha.v8n6p41

\begin{abstract}
Objective: Healthcare institutions have taken efforts to communicate to their healthcare workers (HCWs) about the concepts and importance of clinical quality and patient safety (CQPS). However, implementing interventions to promote pro-CQPS behaviour without fully evaluating the factors that direct such behaviour may be costly and counter-productive. This study aimed to investigate HCWs' perception of their competence and attitudes towards CQPS. It also looked into their perceived behaviour pattern to unsafe practices and usefulness of the different avenues to improve CQPS behavior in the hospital.

Methods: A survey was conducted among doctors, nurses and allied health workers over two months in 2017. Paper surveys were distributed during departmental staff meetings. Participation was strictly voluntary, and responses were de-identified and kept confidential. Responses were measured using a five-point Likert scale. Data was analyzed using descriptive statistics.

Results: The participation rate was $90.2 \%$ (541/600). Of the respondents, $88.0 \%$ and $85.6 \%$ agreed that CQPS was important and relevant to their work respectively. However, when asked if they execute a series of pro-CQPS behaviour, results showed a knowledge-behaviour disconnect. Only $36.2 \%$ will intervene when they see unsafe practice and $27.2 \%$ see the importance of reporting near miss events.

Conclusions: While respondents are generally aware of the importance and relevance of CQPS, this is not reflected in their behaviour as they are unmotivated and show disinterest in practising pro-CQPS behaviour. Further studies are needed to address the factors associated with this knowledge-behaviour disconnect.
\end{abstract}

Key Words: Behaviour, Awareness, Clinical quality, Patient safety, Communication

\section{INTRODUCTION}

Since the publication of the Institute of Medicine (IOM)'s highly influential report, To Err is Human, ${ }^{[1]}$ in 2000 , achieving high standards in clinical quality and patient safety (CQPS) has been a key goal of healthcare organizations worldwide. The goal of CQPS is to minimize adverse events and eliminate preventable harm in healthcare. ${ }^{[2]}$ Unfortunately, hospitals are still not absolute safe places of healing. The risk of adverse medical events and patient harm still exists.

\footnotetext{
*Correspondence: Adeline Shuhan Koh; Email: adeline_koh@nuhs.edu.sg; Address: Department of Medical Affairs, Ng Teng Fong General Hospital, JurongHealth Campus, A Member of National University Health System, Singapore.
} 
The extent and details of error rates associated with preventable adverse medical events in the hospitals of Singapore are not easily accessed. However, it was reported that there were approximately 281 serious reportable events reported to the Ministry of Health in 2017, ${ }^{[3]}$ with 8 of such cases resulting in severe patient outcome. Many studies reported similar prevalence of adverse medical events, ${ }^{[4-7]}$ proving that there is an international consensus that standards in CQPS have left much to be desired.

Safety culture is an aspect of patient safety that is expected to significantly contribute to improving CQPS. ${ }^{[1]}$ In a 2009 report by $\mathrm{WHO},{ }^{[9]}$ it was indicated that organizations need to change their culture to make it "easy to do the right thing, and hard to do the wrong thing" for patient care. Studies have shown that the knowledge, attitudes and pattern of behaviors of healthcare workers (HCWs) influence the overall organizational culture of safety. ${ }^{[10-12]}$

The purpose of this study is to investigate the current attitude of the HCWs working in the study hospital. This may shed light into guiding future efforts in improving CPQS attitude and behavior in the hospital.

\section{STUdy}

\subsection{Methodology}

The survey instrument was developed after studying the Agency for Health Care Research and Quality (AHRQ) surveys of patient safety culture. ${ }^{[13]}$ AHRQ developed the patient safety culture survey after having reviewed existing literature and surveys, pertaining to patient safety, hospital medical errors, safety climate and cultures and conducted background interviews with experts in the field of patient safety and with hospital staff. The Joint Commision also provided input to the survey. ${ }^{[13]}$ Survey questions were adapted and formulated in such a way that they would fit the context of the study hospital and categorized into five main domains. Domains included current awareness of CQPS concepts (e.g. "I know what to do when I see an unsafe practice"), attitudes towards CQPS (e.g. "I may not want to intervene when I see unsafe practices"), reaction towards CQPS communications and trainings (e.g. "I make time to attend CQPS events"), effectiveness of CQPS communications (e.g. "The information in the patient safety publications is relevant to me"), and other factors affecting the effectiveness of these efforts (e.g. "Senior management sees CQPS as a priority"). Details of the survey can be found in the supplementary attachement.

The study team had pilot-tested the survey with $15 \mathrm{HCWs}$, comprising of doctors, nurses and allied health professionals. Varied responses to the survey questions were received which validated the need to proceed with this study. Revisions were made to the forms based on feedback gathered before distributing to the study sample. This study was approved by the ethics committee in Singapore for waiver of consent.

The survey was conducted in a 700-bed acute adult tertiary hospital in Singapore from May 1, 2017 through June 30, 2017. The target population are staffs who are directly involved in providing patient care as they play a direct and determining role in setting the hospital's CQPS standards. As such, HCWs from all medical, nursing and allied health disciplines within the hospital were included in the survey. There was an estimate of a total of 4,000 HCWs (medical, nursing, allied health) in the study hospital.

The survey involved completing a written questionnaire. The questionaire and an explanatory note explaining the purpose of the survey were distributed during departmental staff meetings. Participation was strictly voluntary and responses were de-identified and kept confidential. Information which would allow identifying of individual respondents, i.e. name, employee number, personal identification number, was not requested in the survey.

Respondents were asked to provide their demographics and job type within the hospital, and to respond to questions in the survey. Responses were measured using a five-point Likert scale, where 1 = strongly disagree; 2 = disagree; $3=$ neutral; 4 = agree; and $5=$ strongly agree. The final section of the questionnaire was open ended, as respondents were asked to write about their preferred mode of communication of knowledge on CQPS.

The primary outcome of this study is to investigate the current attitude of the HCWs working in the study hospital. The secondary outcomes are the HCW's perceived behavioural pattern to unsafe practices and the usefulness of the different avenues to improve CQPS behavior in the hospital.

\subsection{Data analysis}

Data collected was entered into a Microsoft Excel spreadsheet for analysis. Data was analysed using descriptive statistics. We reported proportions of the positive and negative responses of different HCWs' groups to the different domains of the survey.

For further analysis, SPSS version 24 was used. The fivepoint Likert scale was used. Strongly agree and agree are considered as a positive response i.e. Yes, strongly disagree and disagree are considered as negative response i.e. No, an incomplete response for that domain is considered as non response, and a neutral response is considered as such, these are consistent throughout all the domains. We reported the proportions of positive and negative responses amongst the HCWs group for the following three domains: (1) current 
awareness of CQPS, (2) attitudes towards CQPS, (3) reaction to CQPS communication efforts.

\section{Results}

\subsection{Recruitment}

There were 600 forms distributed in May 2017 to HCWs from medical, nursing and allied health disciplines, regardless of level of seniority and work experience. The study team consolidated responses over a two-month period which coincided with two, monthly compulsory departmental briefings, this would have enabled us to capture majority of the respondents. The participation rate for the study was $90.2 \%$ (541/600). There were 170 incomplete forms received. Table 1 shows the baseline features of the study population.

Table 1. Baseline characteristics of the study population $(\mathrm{N}=541)$

\begin{tabular}{|c|c|}
\hline Variable & \\
\hline Gender & n $(\%)$ \\
\hline - Male & $134(24.8)$ \\
\hline - Female & $393(72.6)$ \\
\hline - Did not indicate gender & $14(2.6)$ \\
\hline Ethnicity & $\mathbf{n}(\%)$ \\
\hline - Chinese & $312(57.7)$ \\
\hline • Malay & $39(7.2)$ \\
\hline - Indian & $91(16.8)$ \\
\hline - Others & $76(14.0)$ \\
\hline - Did not indicate ethnicity & $23(4.3)$ \\
\hline Age Group & Median Age (Interquartile range) \\
\hline - Medical & $35.5(20)$ \\
\hline - Nursing & $25.5(10)$ \\
\hline - Allied Health & $25.5(10)$ \\
\hline Area of Work & $\mathrm{n}(\%)$ \\
\hline • Medical & $140(25.9)$ \\
\hline • Nursing & $248(45.8)$ \\
\hline - Allied Health & $139(25.7)$ \\
\hline - Did not indicate area of work & $14(2.6)$ \\
\hline Length of service & $\mathrm{n}(\%)$ \\
\hline$\bullet<1$ year & $57(10.5)$ \\
\hline - 1 to 5 years & $280(51.8)$ \\
\hline - 6 to 10 years & $89(16.5)$ \\
\hline$\bullet>10$ years & $98(18.1)$ \\
\hline - Did not indicate length of service & $17(3.1)$ \\
\hline
\end{tabular}

\subsection{Primary outcome}

Table 2 shows the primary outcome of the study: The respondents' current attitudes towards CQPS.

More than $80 \%$ of the respondents felt that CQPS was important and agreed that CQPS was relevant to their work. However, more nurses and allied health professionals stated that they may not want to intervene when they see unsafe practices, and that they do not think reporting near misses is important.

\subsection{Secondary outcomes}

Tables 3-4 show the secondary outcomes of the study.

\subsubsection{Current awareness of CQPS}

Table 3 shows the results of the respondents' current awareness of CQPS.

Over $50 \%$ of the respondents rated themselves as having sufficient knowledge on CQPS concepts and believed that they have better knowledge of CQPS as compared to a year ago. Notably, less doctors and allied health professionals rated these two questions positively as compared to the nurses.

Only $31.1 \%$ felt that they have received sufficient training in CQPS, and similarly with a smaller percentage from doctors and allied health professionals.

\subsubsection{Usefulness of CQPS communication efforts}

Table 4 shows the results of the usefulness of CQPS communication efforts to improve CQPS behavior in the hospital.

Only $355(65.6 \%)$ of the respondents reported that their departments make time to communicate CQPS information. Only approximately $50.0 \%$ of the respondents reported that their department's patient safety representatives actively communicate CQPS information and are familiar with related information.

Out of all the respondents, 285 (52.7\%) indicated that reading CQPS publications is of low priority to them. Notably, only $39(27.9 \%)$ doctors read every issue of the patient safety publications. Only 299 (55.3\%) of the respondents expressed interest in attending CQPS related events. Medical (58/140, $41.4 \%)$ and allied health $(59 / 139,42.4 \%)$ groups showed less interest in such events, as compared to nursing group $(176 / 248,71.0 \%)$.

\section{Discussion}

Our study shows that HCWs are aware and know of the importance of CQPS, however there is a knowledge behavior disconnect. The awareness is not translated into actual practice.

HCWs are generally reluctant to get actively involved in CQPS and such indifference has been a global and longstanding issue. ${ }^{[14-19]}$ It is an ongoing challenge for healthcare institutions to overcome this lack of engagement. The results of this study showed that despite multiple communication fronts and efforts, response seemed lukewarm in the appraisal of the extent to which these initiatives had engaged them with CQPS. 
Table 2. Questions determining respondents' attitudes towards CQPS $(\mathrm{N}=541)$

\begin{tabular}{|c|c|c|c|c|c|c|}
\hline Denominator & & $\mathrm{N}=541$ & $\mathrm{~N}=140$ & $\mathrm{~N}=\mathbf{2 4 8}$ & $\mathrm{N}=139$ & $\mathrm{~N}=14$ \\
\hline Question & Response & n (\%) & Medical (\%) & Nursing (\%) & Allied (\%) & Dept not specified (\%) \\
\hline \multirow{7}{*}{$\begin{array}{l}\text { I feel CQPS is } \\
\text { important. }\end{array}$} & \multirow[t]{2}{*}{ Yes } & 476 & 117 & 221 & 124 & 14 \\
\hline & & $(88.0)$ & (83.6) & (89.1) & (89.2) & (100.0) \\
\hline & \multirow[t]{2}{*}{ No } & 59 & 22 & 22 & 15 & \\
\hline & & (10.9) & (15.7) & (8.9) & (10.8) & - \\
\hline & \multirow[t]{2}{*}{ Non Response } & 6 & 1 & 5 & & \\
\hline & & (1.1) & $(0.7)$ & (2.0) & - & - \\
\hline & Neutral & - & - & - & - & - \\
\hline \multirow{7}{*}{$\begin{array}{l}\text { CQPS is relevant to my } \\
\text { work. }\end{array}$} & \multirow[t]{2}{*}{ Yes } & 463 & 119 & 215 & 118 & 11 \\
\hline & & (85.6) & $(85.0)$ & (86.7) & (84.9) & (78.6) \\
\hline & \multirow[t]{2}{*}{ No } & 57 & 14 & 23 & 18 & 2 \\
\hline & & $(10.5)$ & $(10.0)$ & $(9.3)$ & (12.9) & (14.3) \\
\hline & \multirow[t]{2}{*}{ Non Response } & 21 & 7 & 10 & 3 & 1 \\
\hline & & (3.9) & (5.0) & $(4.0)$ & (2.2) & (7.1) \\
\hline & Neutral & - & - & - & - & - \\
\hline \multirow{7}{*}{$\begin{array}{l}\text { I am motivated to apply } \\
\text { what I have learnt about } \\
\text { CQPS at my work. }\end{array}$} & \multirow[t]{2}{*}{ Yes } & 405 & 99 & 197 & 102 & 7 \\
\hline & & (74.9) & (70.7) & (79.4) & (73.4) & $(50.0)$ \\
\hline & \multirow[t]{2}{*}{ No } & 125 & 37 & 46 & 35 & 7 \\
\hline & & (23.1) & (26.5) & (18.6) & $(25.2)$ & $(50.0)$ \\
\hline & \multirow[t]{2}{*}{ Non Response } & 6 & 1 & 3 & 2 & 8 \\
\hline & & (1.1) & $(0.7)$ & (1.2) & (1.4) & - \\
\hline & Neutral & $\begin{array}{c}5 \\
(0.9)\end{array}$ & $\begin{array}{c}3 \\
(2.1)\end{array}$ & $\begin{array}{c}2 \\
(0.8)\end{array}$ & - & - \\
\hline \multirow{6}{*}{$\begin{array}{l}\text { I may not want to } \\
\text { intervene when I see } \\
\text { unsafe practices. }\end{array}$} & Yes & $\begin{array}{c}196 \\
(36.2)\end{array}$ & $\begin{array}{c}34 \\
(24.3)\end{array}$ & $\begin{array}{c}107 \\
(43.1)\end{array}$ & $\begin{array}{c}50 \\
(36.0)\end{array}$ & $\begin{array}{c}5 \\
(35.7)\end{array}$ \\
\hline & \multirow[t]{2}{*}{ No } & 337 & 104 & 135 & 89 & 9 \\
\hline & & (62.3) & (74.3) & (54.4) & (64.0) & (64.3) \\
\hline & \multirow[t]{2}{*}{ Non Response } & 8 & 2 & 6 & 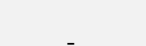 & . \\
\hline & & (1.5) & (1.4) & (2.4) & - & \\
\hline & Neutral & - & - & - & & \\
\hline \multirow{7}{*}{$\begin{array}{l}\text { I do not think reporting } \\
\text { near misses is } \\
\text { important. }\end{array}$} & \multirow[t]{2}{*}{ Yes } & 147 & 28 & 76 & 39 & 4 \\
\hline & & $(27.2)$ & $(20.0)$ & $(30.6)$ & $(28.1)$ & (28.6) \\
\hline & \multirow[t]{2}{*}{ No } & 385 & 110 & 166 & 99 & 10 \\
\hline & & (71.2) & (78.6) & (66.9) & (71.2) & (71.4) \\
\hline & \multirow[t]{2}{*}{ Non Response } & 9 & 2 & 6 & 1 & \\
\hline & & (1.7) & (1.4) & (2.4) & $(0.7)$ & - \\
\hline & Neutral & - & - & - & - & - \\
\hline \multirow{8}{*}{$\begin{array}{l}\text { I see incident reporting } \\
\text { positively. }\end{array}$} & \multirow[t]{2}{*}{ Yes } & 401 & 106 & 191 & 94 & 10 \\
\hline & & (74.1) & (75.7) & (77.0) & (67.6) & (71.4) \\
\hline & \multirow[t]{2}{*}{ No } & 125 & 33 & 48 & 42 & 2 \\
\hline & & (23.1) & (23.6) & (19.4) & $(30.2)$ & (14.3) \\
\hline & Non Response & 7 & 1 & 5 & 1 & \\
\hline & & (1.3) & $(0.7)$ & (2.0) & $(0.7)$ & - \\
\hline & Neutral & 8 & - & 4 & 2 & 2 \\
\hline & & (1.8) & - & (1.6) & (1.4) & (14.3) \\
\hline
\end{tabular}

Note. CQPS: Clinical Quality and Patient Safety. The five-point Likert scale: Strongly agree and agree are considered as a positive response i.e. Yes and negative responses are considered a negative response i.e. No, an incomplete response for that domain is considered as non response and a neutral response is considered as such.

Almost half of the respondents in the medical and allied health groups assessed themselves to have insufficient knowledge on CQPS concepts and did not think that their level of knowledge improved over the past one year. However, when offered with CQPS events and communication material targeted to engage them and increase their knowledge, respondents seemed to show limited interest, particularly the medical group.
The results also found a knowledge-behaviour disconnect. While respondents may agree that CQPS is important and see the relevance of CQPS to their work, it was not reflected in their behaviour. For instance, speaking up is an important behavior which promotes CQPS as it highlights gaps and contributes to improvement. "Frontline staff, such as nurses, is well positioned to observe early signs of unsafe conditions in care delivery and bring them to the attention of the organi- 
zation."[20] However, a large number from the nurses group stated that they may not want to intervene when they witness unsafe practices. This study echoed several studies which pointed out the challenge nurses face when trying to speak up, quoting moral distress to intervene due to power dynamic and worries of increasing discord with other HCWs as they may sometimes be unsure if they possess authority over other professionals "Hesitance in speaking up or failure to indicate or correct errors can be caused by disproportionate authority gradients, excessive professional courtesy". ${ }^{[20]}$ A Patient Safety Survey by Agency for Healthcare Research and Quality (AHRQ) indicated that $47 \%$ of respondents said that it feels like unsafe event reports are held against them". [21]

Having a robust reporting system is a crucial step in building a positive CQPS culture within a hospital. "Effective patient safety events reporting, is a mainstay of efforts to detect patient safety events and quality problems." ${ }^{[22]}$ Yet, respondents from all groups deemed reporting near misses to be unimportant, leaving this reporting culture much to be desired. A study by The Institute for Safe Medication Practices has similarly reported that $40 \%$ percent of clinicians either keep quiet or remain passive after witnessing an improper patient care event. ${ }^{[23]}$

From this study, it was found that the level of influence and involvement from the patient safety representatives as well as supervisors in promoting pro-CQPS actions appeared to be low for the medical group. More than half of the respondents in medical group rated their supervisors as uncommitted. Using this result of the study, the organization could explore the possibility of improving the active involvement of patient safety representatives in promoting pro-CQPS attitudes and actions. The Institue of Health Improvement states that assigning a designated safety champion in every department demonstrates the organization's commitment to safety and encourages the staff to share information and ask questions. ${ }^{[24]}$

Table 3. Questions determining respondents' awareness of CQPS $(\mathrm{N}=541)$

\begin{tabular}{|c|c|c|c|c|c|c|}
\hline Denominator & & $N=541$ & $N=140$ & $N=248$ & $\mathrm{~N}=139$ & $\mathrm{~N}=14$ \\
\hline Question & Response & $\mathbf{n}(\%)$ & Medical (\%) & Nursing (\%) & Allied (\%) & Dept not specified (\%) \\
\hline \multirow{8}{*}{$\begin{array}{l}\text { I have sufficient } \\
\text { knowledge on CQPS } \\
\text { concepts. }\end{array}$} & \multirow[t]{2}{*}{ Yes } & 313 & 68 & 167 & 71 & 7 \\
\hline & & $(57.9)$ & (48.6) & $(67.3)$ & $(51.1)$ & $(50.0)$ \\
\hline & \multirow[t]{2}{*}{ No } & 205 & 63 & 69 & 66 & 7 \\
\hline & & (37.9) & (45) & $(27.8)$ & $(47.5)$ & $(50.0)$ \\
\hline & \multirow[t]{2}{*}{ Non Response } & 8 & 3 & 4 & 1 & \\
\hline & & (1.5) & $(2.1)$ & (1.6) & $(0.7)$ & - \\
\hline & \multirow[t]{2}{*}{ Neutral } & 15 & 6 & 8 & 1 & \\
\hline & & $(2.8)$ & (4.3) & (3.2) & $(0.7)$ & \\
\hline \multirow{7}{*}{$\begin{array}{l}\text { I know what to do when I } \\
\text { see an unsafe practice. }\end{array}$} & \multirow[t]{2}{*}{ Yes } & 453 & 110 & 224 & 111 & 8 \\
\hline & & (83.7) & (78.6) & (90.3) & (79.9) & $(57.1)$ \\
\hline & \multirow[t]{2}{*}{ No } & 86 & 30 & 23 & 27 & 6 \\
\hline & & (15.9) & (21.4) & $(9.3)$ & (19.4) & (42.9) \\
\hline & \multirow[t]{2}{*}{ Non Response } & 2 & 0 & 1 & 1 & 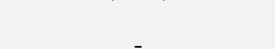 \\
\hline & & $(0.4)$ & $(0.0)$ & $(0.4)$ & $(0.7)$ & - \\
\hline & Neutral & - & - & - & - & - \\
\hline \multirow{8}{*}{$\begin{array}{l}\text { I have better knowledge } \\
\text { about CQPS now as } \\
\text { compared to a year ago. }\end{array}$} & \multirow[t]{2}{*}{ Yes } & 293 & 64 & 155 & 69 & 5 \\
\hline & & $(54.2)$ & (45.7) & $(62.5)$ & (49.6) & (35.7) \\
\hline & \multirow[t]{2}{*}{ No } & 240 & 74 & 90 & 67 & 9 \\
\hline & & (44.4) & $(52.9)$ & $(36.3)$ & (48.2) & (64.3) \\
\hline & \multirow[t]{2}{*}{ Non Response } & 5 & 1 & 3 & 1 & \\
\hline & & $(0.9)$ & $(0.7)$ & (1.2) & $(0.7)$ & - \\
\hline & \multirow[t]{2}{*}{ Neutral } & 3 & 1 & & 2 & \\
\hline & & (0.6) & $(0.7)$ & - & (1.4) & \\
\hline \multirow{7}{*}{$\begin{array}{l}\text { I received sufficient } \\
\text { training in CQPS. }\end{array}$} & \multirow[t]{2}{*}{ Yes } & 168 & 39 & 102 & 25 & 2 \\
\hline & & (31.1) & (27.9) & (41.1) & $(18.0)$ & (14.3) \\
\hline & \multirow[t]{2}{*}{ No } & 369 & 100 & 144 & 113 & 12 \\
\hline & & $(68.2)$ & (71.4) & $(58.1)$ & (81.3) & (85.7) \\
\hline & \multirow[t]{2}{*}{ Non Response } & 4 & 1 & 2 & 1 & \\
\hline & & (0.7) & $(0.7)$ & (0.8) & $(0.7)$ & - \\
\hline & Neutral & - & - & - & - & - \\
\hline
\end{tabular}

Note. CQPS: Clinical Quality and Patient Safety. The five-point Likert scale: Strongly agree and agree are considered as a positive response i.e. Yes and negative responses are considered a negative response i.e. No, an incomplete response for that domain is considered as non response and a neutral response is considered as such. 
Table 4. Questions determining the respondents' reaction to CQPS communication efforts

\begin{tabular}{|c|c|c|c|c|c|c|}
\hline Denominator & & $N=541$ & $\mathrm{~N}=140$ & $N=248$ & $\mathrm{~N}=139$ & $\mathrm{~N}=14$ \\
\hline Question & Response & $\mathrm{n}(\%)$ & Medical (\%) & Nursing (\%) & Allied Health (\%) & Dept not specified (\%) \\
\hline \multirow{4}{*}{$\begin{array}{l}\text { My department makes time to } \\
\text { communicate CQPS } \\
\text { information. }\end{array}$} & Yes & $\begin{array}{c}355 \\
(65.6)\end{array}$ & $\begin{array}{c}81 \\
(57.9)\end{array}$ & $\begin{array}{c}171 \\
(69.0)\end{array}$ & $\begin{array}{c}97 \\
(70.0)\end{array}$ & $\begin{array}{c}6 \\
(42.9)\end{array}$ \\
\hline & No & $\begin{array}{c}181 \\
(33.5)\end{array}$ & $\begin{array}{c}57 \\
(40.7)\end{array}$ & $\begin{array}{c}75 \\
(30.2)\end{array}$ & $\begin{array}{c}41 \\
(29.5)\end{array}$ & $\begin{array}{c}8 \\
(57.1)\end{array}$ \\
\hline & Non Response & $\begin{array}{c}5 \\
(0.9)\end{array}$ & $\begin{array}{c}2 \\
(1.4)\end{array}$ & $\begin{array}{c}2 \\
(0.8)\end{array}$ & $\begin{array}{c}1 \\
(0.7)\end{array}$ & - \\
\hline & Neutral & - & - & - & - & - \\
\hline \multirow{4}{*}{$\begin{array}{l}\text { My department's patient safety } \\
\text { representative is familiar with } \\
\text { CQPS related information. }\end{array}$} & Yes & $\begin{array}{c}272 \\
(50.3)\end{array}$ & $\begin{array}{c}57 \\
(40.7)\end{array}$ & $\begin{array}{c}153 \\
(61.7)\end{array}$ & $\begin{array}{c}57 \\
(41.0)\end{array}$ & $\begin{array}{c}5 \\
(35.7)\end{array}$ \\
\hline & No & $\begin{array}{c}253 \\
(46.8)\end{array}$ & $\begin{array}{c}78 \\
(55.7)\end{array}$ & $\begin{array}{c}85 \\
(34.3)\end{array}$ & $\begin{array}{c}81 \\
(58.3)\end{array}$ & $\begin{array}{c}9 \\
(64.3)\end{array}$ \\
\hline & Non Response & $\begin{array}{c}9 \\
(1.7)\end{array}$ & $\begin{array}{c}4 \\
(2.9)\end{array}$ & $\begin{array}{c}4 \\
(1.6)\end{array}$ & $\begin{array}{c}1 \\
(0.7)\end{array}$ & - \\
\hline & Neutral & $\begin{array}{c}7 \\
(1.3)\end{array}$ & $\begin{array}{c}1 \\
(0.7)\end{array}$ & $\begin{array}{c}6 \\
(2.4)\end{array}$ & - & - \\
\hline \multirow{4}{*}{$\begin{array}{l}\text { My department's patient safety } \\
\text { representative actively shares } \\
\text { CQPS communications. }\end{array}$} & Yes & $\begin{array}{c}299 \\
(55.3)\end{array}$ & $\begin{array}{c}56 \\
(40.0)\end{array}$ & $\begin{array}{c}168 \\
(67.7)\end{array}$ & $\begin{array}{c}70 \\
(50.4)\end{array}$ & $\begin{array}{c}5 \\
(35.7)\end{array}$ \\
\hline & No & $\begin{array}{c}230 \\
(42.5)\end{array}$ & $\begin{array}{c}81 \\
(57.9)\end{array}$ & $\begin{array}{c}74 \\
(29.8)\end{array}$ & $\begin{array}{c}66 \\
(47.5)\end{array}$ & $\begin{array}{c}9 \\
(64.3)\end{array}$ \\
\hline & Non Response & $\begin{array}{c}12 \\
(2.2)\end{array}$ & $\begin{array}{c}3 \\
(2.1)\end{array}$ & $\begin{array}{c}6 \\
(2.4)\end{array}$ & $\begin{array}{c}3 \\
(2.2)\end{array}$ & - \\
\hline & Neutral & - & - & - & - & - \\
\hline \multirow{4}{*}{$\begin{array}{l}\text { I read almost every issue of the } \\
\text { patient safety publications. }\end{array}$} & Yes & $\begin{array}{c}287 \\
(53.0)\end{array}$ & $\begin{array}{c}39 \\
(27.9)\end{array}$ & $\begin{array}{c}171 \\
(69.0)\end{array}$ & $\begin{array}{c}69 \\
(50.0)\end{array}$ & $\begin{array}{c}8 \\
(57.1)\end{array}$ \\
\hline & No & $\begin{array}{c}250 \\
(46.2)\end{array}$ & $\begin{array}{c}100 \\
(71.4)\end{array}$ & $\begin{array}{c}75 \\
(30.2)\end{array}$ & $\begin{array}{c}70 \\
(50.4)\end{array}$ & $\begin{array}{c}5 \\
(35.7)\end{array}$ \\
\hline & Non Response & $\begin{array}{c}4 \\
4 \\
(0.7)\end{array}$ & $\begin{array}{l}1 \\
(0.7)\end{array}$ & $\begin{array}{c}2 \\
2 \\
(0.8)\end{array}$ & - & $\begin{array}{c}1 \\
(7.1)\end{array}$ \\
\hline & Neutral & - & - & - & - & - \\
\hline \multirow{4}{*}{$\begin{array}{l}\text { I read almost every memo sent } \\
\text { by the senior management. }\end{array}$} & Yes & $\begin{array}{c}346 \\
(64.0)\end{array}$ & $\begin{array}{c}70 \\
(50.0)\end{array}$ & $\begin{array}{l}185 \\
(74.6)\end{array}$ & $\begin{array}{c}85 \\
(61.2)\end{array}$ & $\begin{array}{c}6 \\
(42.9)\end{array}$ \\
\hline & No & $\begin{array}{c}187 \\
(34.6)\end{array}$ & $\begin{array}{c}66 \\
(47.1)\end{array}$ & $\begin{array}{c}59 \\
(23.8)\end{array}$ & $\begin{array}{c}54 \\
(38.8)\end{array}$ & $\begin{array}{c}8 \\
(57.1)\end{array}$ \\
\hline & Non Response & $\begin{array}{c}8 \\
(1.5)\end{array}$ & $\begin{array}{c}4 \\
(2.9)\end{array}$ & $\begin{array}{c}4 \\
(1.6)\end{array}$ & - & - \\
\hline & Neutral & & - & - & - & - \\
\hline \multirow{4}{*}{$\begin{array}{l}\text { I do not look for CQPS } \\
\text { information on the Intranet. }\end{array}$} & Yes & $\begin{array}{c}372 \\
(68.8)\end{array}$ & $\begin{array}{c}116 \\
(82.9)\end{array}$ & $\begin{array}{l}138 \\
(55.6)\end{array}$ & $\begin{array}{l}106 \\
(76.3)\end{array}$ & $\begin{array}{c}12 \\
(85.7)\end{array}$ \\
\hline & No & $\begin{array}{c}163 \\
(30.1)\end{array}$ & $\begin{array}{c}22 \\
(15.7)\end{array}$ & $\begin{array}{c}106 \\
(42.7)\end{array}$ & $\begin{array}{c}33 \\
(23.7)\end{array}$ & $\begin{array}{c}2 \\
(14.3)\end{array}$ \\
\hline & Non Response & $\begin{array}{c}6 \\
(1.1)\end{array}$ & $\begin{array}{c}2 \\
(1.4)\end{array}$ & $\begin{array}{c}4 \\
(1.6)\end{array}$ & - & - \\
\hline & Neutral & - & - & - & - & - \\
\hline \multirow{4}{*}{$\begin{array}{l}\text { I am interested to attend CQPS } \\
\text { events. }\end{array}$} & Yes & $\begin{array}{l}299 \\
(55.3)\end{array}$ & $\begin{array}{c}58 \\
(41.4)\end{array}$ & $\begin{array}{l}176 \\
(71.0)\end{array}$ & $\begin{array}{c}59 \\
(42.4)\end{array}$ & $\begin{array}{c}6 \\
(42.9)\end{array}$ \\
\hline & No & $\begin{array}{c}218 \\
(40.3)\end{array}$ & $\begin{array}{c}72 \\
(51.4)\end{array}$ & $\begin{array}{c}64 \\
(25.8)\end{array}$ & $\begin{array}{c}74 \\
(53,2)\end{array}$ & $\begin{array}{c}8 \\
(57.1)\end{array}$ \\
\hline & Non Response & $\begin{array}{l}10 \\
(1.8)\end{array}$ & $\begin{array}{c}4 \\
(29)\end{array}$ & $\begin{array}{c}5 \\
5\end{array}$ & $\begin{array}{c}1 \\
(07)\end{array}$ & - \\
\hline & Neutral & $\begin{array}{c}14 \\
(2.6)\end{array}$ & $\begin{array}{c}6 \\
(4.3)\end{array}$ & $\begin{array}{c}3 \\
(1.2)\end{array}$ & $\begin{array}{c}5 \\
(3.6)\end{array}$ & \\
\hline \multirow{4}{*}{$\begin{array}{l}\text { I make time to attend CQPS } \\
\text { events. }\end{array}$} & Yes & $\begin{array}{c}203 \\
(37.5)\end{array}$ & $\begin{array}{c}33 \\
(23.6)\end{array}$ & $\begin{array}{c}133 \\
(53.6)\end{array}$ & $\begin{array}{c}32 \\
(23.0)\end{array}$ & $\begin{array}{c}5 \\
(35.7)\end{array}$ \\
\hline & No & $\begin{array}{c}330 \\
(61.0)\end{array}$ & $\begin{array}{c}105 \\
(75.0)\end{array}$ & $\begin{array}{c}110 \\
(44.4)\end{array}$ & $\begin{array}{c}106 \\
(76.3)\end{array}$ & $\begin{array}{c}9 \\
(64.3)\end{array}$ \\
\hline & Non Response & $\begin{array}{c}8 \\
(1.5)\end{array}$ & $\begin{array}{c}2 \\
(1.4)\end{array}$ & $\begin{array}{c}5 \\
(2.0)\end{array}$ & $\begin{array}{c}1 \\
(0.7)\end{array}$ & - \\
\hline & Neutral & - & - & - & - & \\
\hline \multirow{4}{*}{$\begin{array}{l}\text { Reading CQPS } \\
\text { communications is of low } \\
\text { priority to me. }\end{array}$} & Yes & $\begin{array}{l}285 \\
(52.7)\end{array}$ & $\begin{array}{c}82 \\
(58.6)\end{array}$ & $\begin{array}{c}124 \\
(50.0)\end{array}$ & $\begin{array}{c}71 \\
(51.1)\end{array}$ & $\begin{array}{c}8 \\
(57.1)\end{array}$ \\
\hline & No & $\begin{array}{c}246 \\
(45.5)\end{array}$ & $\begin{array}{c}56 \\
(40.0)\end{array}$ & $\begin{array}{c}120 \\
(48.4)\end{array}$ & $\begin{array}{c}64 \\
(46.0)\end{array}$ & $\begin{array}{c}6 \\
(42.9)\end{array}$ \\
\hline & Non Response & 6 & $\begin{array}{c}2 \\
(1.4)\end{array}$ & $\begin{array}{c}3 \\
(1.2)\end{array}$ & $\begin{array}{c}1 \\
(0.7)\end{array}$ & - \\
\hline & Neutral & $\begin{array}{c}4 \\
(0.7)\end{array}$ & - & $\begin{array}{c}1 \\
(0.4)\end{array}$ & $\begin{array}{c}3 \\
(2.2)\end{array}$ & - \\
\hline \multirow{6}{*}{$\begin{array}{l}\text { My supervisor is committed to } \\
\text { CQPS. }\end{array}$} & Yes & $\begin{array}{c}298 \\
(55.1)\end{array}$ & $\begin{array}{c}60 \\
(42.9)\end{array}$ & $\begin{array}{c}148 \\
(60.0)\end{array}$ & $\begin{array}{c}85 \\
(61.2)\end{array}$ & $\begin{array}{c}5 \\
(35.7)\end{array}$ \\
\hline & No & 212 & 73 & 84 & 46 & 9 \\
\hline & & $(39.2)$ & $(52.1)$ & (33.9) & $(33.1)$ & (64.3) \\
\hline & Non Response & $\begin{array}{c}10 \\
(1.1)\end{array}$ & $\begin{array}{c}5 \\
(3.6)\end{array}$ & $\begin{array}{c}4 \\
(1.6)\end{array}$ & $\begin{array}{c}1 \\
(0.7)\end{array}$ & - \\
\hline & Neutral & 21 & 2 & 12 & 7 & \\
\hline & & (3.9) & (1.4) & (4.8) & (5) & \\
\hline
\end{tabular}

Note. CQPS: Clinical Quality and Patient Safety. The five-point Likert scale: Strongly agree and agree are considered as a positive response i.e. Yes and negative responses are considered a negative response i.e. No, an incomplete response for that domain is considered as non response and a neutral response is considered as such. 
This study shows that the HCWs are neither motivated nor engaged to put CQPS into actual practice. This is worrisome and moving forwards, there is an urgent need for the institution to deep dive into factors contributing to this disengagement. The potential of direct observations on the ground and qualitative interviews with HCWs will allow us to gain better insight into the root causes of this knowledgebehaviour disconnect. With a better understanding of the root causes, focused measures can then be undertaken to resolve issues contributing to this knowledge-behaviour disconnect.

\section{Conclusion}

Our study re-inforces that HCWs across all groups, i.e. medical, nursing and allied health have reported awareness that CQPS is important. However, our study shows that this awareness has not translated into actual practice.

We can then direct our efforts to find reasons for this disconnect and strategise advances to translate this awareness to actual practice of patient safety.

\section{Limitations}

The results of this study should be interpreted in the light of several limitations. This was a single-institution experience, and results may not be generalisable to other hospitals. Results were based entirely on the HCWs' attitude expressed during the survey and did not include any observed changes in behaviour. The use of self-administered quesitonaires may also allow respondents to over- or under- report attitudes and practice. Selection bias ought to be taken into account, as the participation of the survey was entirely voluntary and we were unable to explore characteristics of non-participants, and we excluded staff who were absent from their departmental meetings. We did not perform a subset analysis based on difference of seniority, analysis of the data was based on their scope of work. We also did not determine the reasons behind the knowledge behavior disconnect, we will look into this in our future study.

\section{CONFLicts OF InTEREST Disclosure}

The authors declare they have no conflicts of interest.

\section{REFERENCES}

[1] Stelfox H, Palmisani S, Orav EJ, et al. The "To Err is Human" report and the patient safety literature. Qual Saf Healthc. 2006 Jun; 15: 174-8. PMid: 16751466. https ://doi.org/10.1136/qshc. 200 6.017947

[2] Emanuel L, Berwick D, Combes J, et al. What Exactly is Patient Safety? Adv Patient Saf New Dir Altern Approaches Vol 1 Assess Rockv MD Agency Healthc Res Qual. 2008 Aug.

[3] Minstry of Health, Singapore. Serious Reportable Events Reported by Public Hospitals/Institutions in 2017. Singapore: Ministry of Health; 2017.

[4] Abdou HA, Saber KM. A baseline assessment of patient safety culture among Nurses at Student University Hospital. World J Med Sci. 2011 Jan; 6: 17-26.

[5] Alayed A, Loof H, Johnansson U. Saudi Arabian ICU safety culture and nurses' attitudes. Int J Health Care Qual Assur. 2014; 27: 581-93. PMid: 25252564. https ://doi .org/10.1108/IJHCQA-04-201 3-0042

[6] Chaboyer W, Chamberlian D, Conroy K. Safety culture in Australian intensive care units: establishing a baseline for quality improvement. Am J Crit Care. 2013; 22: 93-102. PMid: 23455858. https://doi.org/10.4037/ajcc2013722

[7] Profit J, Etchegaray J, Peterson L, et al. Neonatal intensive care unit safety culture varies widely. Arch Child Fetal Neonatal Ed. 2012; 1-17. https://doi.org/10.1016/j.ynpm.2012.06.071

[8] Flotta D, Rizza P, Bianco A, et al. Patient Safety and Medical Errors: Knowledge, attitudes and behavior among Italian hospital physicians. Int J Qual Health Care. 2012 Jun; 24: 258-65. PMid: 22490299. https://doi.org/10.1093/intqhc/mzs014

[9] Flin R, Jackson J, Sarac C. Human Factors in Patient Safety: Review of Topics and Tools. World Health Organ. 2009.
[10] Naveh E, Katz N, Stern Z. Treatment errors in healthcare: a safety climate approach. Manage Sci. 2005; 51: 948-60. https ://doi .or $\mathrm{g} / 10.1287 / \mathrm{mnsc} .1050 .0372$

[11] Hofmann D, Mark A. An investigation of the relationship between safety climate and medication errors as well as other nurse and patient outcomes. Pers Psychol. 2006; 59: 847-69. https://doi.or $\mathrm{g} / 10.1111 / \mathrm{j} .1744-6570.2006 .00056 . \mathrm{x}$

[12] Zohar D, Livne Y, Tenne G. Healthcare climate: A framework for measuring and improving patient safety. Crit Care Med. 2007; 35: 1312-7. PMid: 17414090. https://doi.org/10.1097/01.CCM $.0000262404 .10203 . \mathrm{C9}$

[13] Hannah K, Schade C, Lomely D. Hospital Administrative Staff vs Nursing Staff Responses to the AHRQ Hospital Survey on Patient Safety Culture. 2008.

[14] Weiner B, Shortell S, Alexander J. Promoting clinical involvement in hospital quality improvement efforts: the effects of top management, board, and physician leadership. Health Serv Res. 1997; 32: 491-510.

[15] Kaissi A. Enhancing Physician Engagement: An International Perspective. International journal of health services: planning, administration, evaluation. Int J Health Serv Plan Adm Eval. 2014; 44: 56792. PMid: 25618990. https://doi.org/10.2190/HS.44.3.h

[16] Joss R, Kogan M. Advancing Quality: Total Quality Management in the National Health Service. Buckingham: Open Univ Press; 1995.

[17] Ovretveit J. Medical participation in and leadership of quality programmes. Journal of Management in Medicine. 1996; 10: 21-8. PMid: 10166029. https://doi .org/10.1108/02689239610146526

[18] Pollitt C. Business approaches to quality improvement: why they are hard for the NHS to swallow. Qual Health Care. 1996; 5: 104-10. PMid: 10158588. https://doi.org/10.1136/qshc.5.2.104

[19] Jorm C, Kam P. Does medical culture limit doctors' adoption of quality improvement? Lessons learnt from Camelot. Journal of Health Serv Res Policy. 2004; 9: 248-51. PMid: 15509412. https://doi.org/10.1258/1355819042250186 
[20] Ayako O, Cordula W, Bart B. Speaking up for patient safety by hospital-based health care professionals: a literature review. BMC Health Serv Res. 2014.

[21] The Joint Commission. Sentinel Event Alert. 2011. Available from: https://www.jointcommission.org/sentinel_event . aspx

[22] Agency for Healthcare Research and Quality (AHRQ). Reporting Patient Safety Events. 2019 Jan. Available from: https ://psnet. ahrq.gov/primer/reporting-patient-safety-events

[23] Wood D. How to Encourage Staff To Point Out Safety Flaws. Available from: https://www.amnhealthcare.com/latest-healt hcare-news/285/1033/

[24] Institute for Healthcare Improvement. Appoint a Safety Champion for every unit. Available from:

http://www.ihi.org/resources/Pages/Changes/Appoin taSafetyChampionf orEveryUnit.aspx 